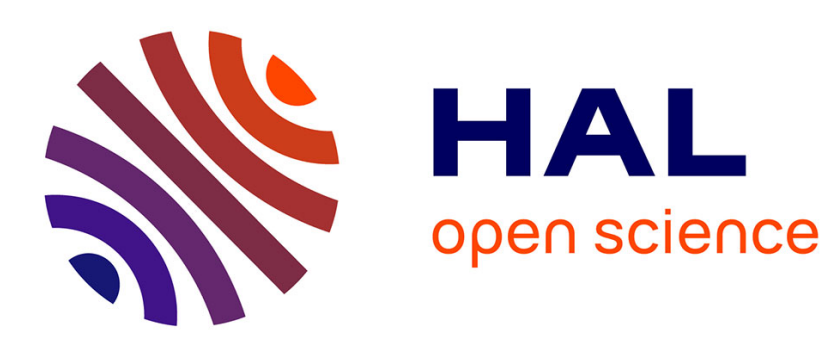

\title{
Dynamics of deformation band formation investigated by high-speed techniques during creep in an AlMg alloy
} A A Shibkov, M A Zheltov, M F Gasanov, A E Zolotov, A A Denisov, M. Lebyodkin

\section{- To cite this version:}

A A Shibkov, M A Zheltov, M F Gasanov, A E Zolotov, A A Denisov, et al.. Dynamics of deformation band formation investigated by high-speed techniques during creep in an AlMg alloy. Materials Science and Engineering: A, 2020, 772, pp.138777. 10.1016/j.msea.2019.138777 . hal-02395028

\section{HAL Id: hal-02395028 \\ https://hal.science/hal-02395028}

Submitted on 5 Dec 2019

HAL is a multi-disciplinary open access archive for the deposit and dissemination of scientific research documents, whether they are published or not. The documents may come from teaching and research institutions in France or abroad, or from public or private research centers.
L'archive ouverte pluridisciplinaire HAL, est destinée au dépôt et à la diffusion de documents scientifiques de niveau recherche, publiés ou non, émanant des établissements d'enseignement et de recherche français ou étrangers, des laboratoires publics ou privés. 


\title{
Dynamics of deformation band formation investigated by high-speed techniques during creep in an AlMg alloy
}

\author{
A.A. Shibkov ${ }^{*}, 1$, M.A. Zheltov ${ }^{1}$, M.F. Gasanov ${ }^{1}$, A.E. Zolotov ${ }^{1}$, A.A. Denisov ${ }^{1}$, M.A. \\ Lebyodkin $^{2}$ \\ ${ }^{1}$ Physics department, Tambov State University, Internationalnaya str. 33, 392000 Tambov, Russia \\ ${ }^{2}$ Laboratoire d'Etude des Microstructures et de Mécanique des Matériaux (LEM3), CNRS, \\ Université de Lorraine, Arts \& Métiers ParisTech, 7 rue Félix Savart, 57070 Metz, France \\ *Corresponding author Shibkov A.A \\ - E-mail address: shibkov@tsu.tmb.ru \\ - Full postal address: Tambov State University, Internationalnaya str. 33, 392000 Tambov, Russia
}

\begin{abstract}
Dynamics of the deformation band formation during creep in an $\mathrm{Al}-\mathrm{Mg}$ alloy was investigated by simultaneous high-speed video recording of deformation bands with an extremely high time resolution of $40 \mu$ s and measurement of the concomitant acoustic emission. The results are consistent with the mechanism where the trigger of a strain step on the creep curve is the nucleation and rapid widening of a primary deformation band, generating an acoustic emission signal within one millisecond. Correlations between various stages of the deformation band formation, acoustic emission, and stress response are explored in detail. Notably, the stress drop rate and the amplitude of the acoustic emission signal are found to be linearly related. The mechanism of the acoustic emission associated with the initial rapid stage of the band development is discussed.
\end{abstract}

Keywords: aluminum alloys, creep, deformation band, high time resolution imaging, acoustic emission

\section{Introduction}

Investigations of the dynamics of plastic deformation, intensely developed since three decades using diverse experimental techniques and modelling approaches, proved that plastic flow of crystalline solids is inherently intermittent and heterogeneous at various length scales. This complexity most generally pertains to a mesoscopic scale range associated with collective dislocation dynamics leading to formation of slip lines or bands but not producing noticeable fluctuations on the deformation curves of bulk samples. In the case of creep, such intermittency results in discontinuous changes in the specimen size with amplitudes about $1 \mu \mathrm{m}$ and less [1-6]. However, some dynamical mechanisms lead to exceptionally strong collective effects when the discontinuities extend to the macroscopic scale of deformation curves. Alloyed materials occupy a special place in this field of research because alloys commonly demonstrate macroscopic plastic instability in various experimental situations. Depending on the conditions, the instability manifests itself as repetitive stress drops in strain-rate controlled tests in a hard tensile machine 
(the Portevin-Le Chatelier effect (PLC) [7]), strain steps in stress-rate controlled tests in a soft machine (the Savart-Masson effect [8]), or strain bursts in creep tests (the "staircase" effect [9]). More specifically, the discontinuous creep gives rise to abrupt strain steps at the primary and secondary creep stages, as observed in Ni-Cr alloys [10-12], austenitic stainless steels [13-15], and Al-based alloys [16-18]. Strain burst magnitudes detected for these materials ranged from about $0.1 \%$ to more than $6 \%$.

The strain steps and stress drops are accompanied by plastic strain localization within deformation bands [18-22]. According to the conventional viewpoint, these plastic instabilities are caused by the dynamic strain aging, i.e., dynamic interactions between mobile dislocations and diffusing impurity atoms [23]. In contrast to the cases of constant strain-rate and constant (non-zero) stress-rate tests, data on the discontinuous creep and the relationships between the strain steps on creep curves and the localization of plastic strain in deformation bands are still very limited. This is an important lack of knowledge for practical applications. While other deformation conditions are particularly essential for the control of the material formability, the operation of most structures usually takes place at a given applied force (gravity, friction, aerodynamic lift, and so on). Therewith, aluminum alloys for automotive and aircraft industries are very sensitive to the strain localization phenomenon, as the sudden failure of such materials in creep conditions usually proceeds along a deformation band occurring in the vicinity of a stress concentrator. Therefore, monitoring of deformation bands is paramount from both the scientific and practical points of view. However, the direct observations of strain localization by various optical methods are usually constrained to the frequency range about $100 \mathrm{~Hz}$ [19-22]. Such techniques are unable to resolve the process of formation of an individual deformation band the entire duration of which was found very early to correspond to a millisecond scale [24]. Optical monitoring in the $\mathrm{kHz}$ frequency range has been implemented only recently $[18,25-27]$ and was mainly applied to the study of the PLC instability (e.g., [25-27]).

Besides direct observations of deformation bands on the specimen surface, other methods make use of various physical responses of the deformed material to the plastic burst. A recent review of experimental methods for studying the deformation band dynamics under conditions of the PLC effect can be found in [28]. It was noted that the acoustic emission (AE) technique [29] provides the best temporal resolution and a high sensitivity for detecting the intermittent plastic flow. Furthermore, as the AE bursts are interpreted as a reply to dislocation avalanches, the continuous AE recording makes possible an "in situ" monitoring of collective deformation processes, delivering real-time information on their dynamics in the frequency range up to 
several $\mathrm{MHz}$ [30-40]. On the other hand, it was pointed out that the strain localization must favor low-frequency components in the $\mathrm{AE}$ spectrum due to an increase in the correlation time between active dislocation ensembles caused, for example, by an avalanche-like unpinning of dislocations from their impurity atmospheres [41]. This feature suggests that a shift in the AE spectrum to a low-frequency domain is an indication of strain localization at a higher length scale, as corroborated by several experimental studies performed under conditions of the PLC effect $[42,43]$.

In the present work, we report on the results of an experimental study of correlations between the dynamics of deformation bands video recorded with an extremely high rate of $25000 \mathrm{fps}$ (frames per second) and $\mathrm{AE}$ responses in the range of $10^{3}-10^{5} \mathrm{~Hz}$ during discontinuous creep in an Al-Mg alloy at room temperature. The choice of such a relatively low frequency range for the $\mathrm{AE}$ technique was motivated by its closeness to the time resolution of the optical method and also by the time scale characteristic of the evolution of deformation bands in aluminum alloys, as documented in the literature: a duration of 0.4-1 ms was reported for the nucleation and transversal growth of an embryo PLC band [26, 27]; the fast stage of the deformation band widening was observed to last about 1-10 $\mathrm{ms}$ under conditions of the discontinuous creep [18]. While high-frequency information on the AE is deliberately sacrificed in such an experimental "time-integration" approach, in comparison with the conventional AE investigations exploring the frequency range $\sim 10^{5}-10^{6} \mathrm{~Hz}$, its advantage stems from the opportunity of establishing a direct correlation between the acoustic and video signals recorded in a similar frequency band. Furthermore, the AE study in this range is expected to supplement the literature data on acoustic emission during intermittent flow, especially during discontinuous creep. Indeed, it is well known that both the discontinuous creep and the PLC effect are accompanied by audible clicks. At the same time, quantitative investigations of the AE have been only performed in the ultrasound frequency band. It would thus be useful to assess the information content in the sound response to the nucleation and development of a deformation band.

\section{Material and methods}

This investigation was performed on a structural aluminum-magnesium AlMg6 (AA5059) alloy, Al-6.15\%Mg-0.65\%Mn-0.25\%Si-0.21\%Fe (wt.\%), which demonstrates pronounced discontinuous creep. Dog-bone specimens with a gauge of $6 \mathrm{~mm} \times 3 \mathrm{~mm} \times 0.2 \mathrm{~mm}$ were cut from the cold-rolled sheet along the rolling direction and subjected to a solution-annealing heat 
treatment at $450{ }^{\circ} \mathrm{C}$ for one hour, followed by quenching in water. This thermal treatment produced a polycrystalline structure of nearly equiaxed grains with an average size about $10 \mu \mathrm{m}$. The tests were carried out in air at room temperature by tension in a constant-load lever-arm creep test machine. The details of the experimental set-up were described in Ref. [18]. A brief outline of essential issues is given below.

Since testing machines usually provide high resolution load measurements, a convenient was to assess the plastic instability on a macroscopic level is to record load drops caused by the abrupt strain bursts and resulting from the partial elastic unloading due to inertia of the “machine-specimen» system. Zemic H3-C3-100 kg-3V load sensor with a sensitivity of 1.5 $\mu \mathrm{V} / \mathrm{N}$ was used for this purpose. The strain was recorded using an optic extensometer-laser triangulation displacement sensor (Riftec) with an accuracy of $1.5 \mu \mathrm{m}$ in the frequency band of $0-2 \mathrm{kHz}$.

The "in situ" monitoring of the formation and propagation of deformation bands on the specimen surface was realized with the aid of a FASTCAM Mini UX100 high-speed digital device camera (Photron) which provided a very high acquisition rate of 25000 fps. To assure a good contrast for the observation of strain localizations, the sample surface was illuminated at a glancing angle and the shot patterns were processed by a computer-assisted subtraction of timeconsecutive images. The video records were synchronized with the measurements of the load, strain, and AE. The AE signal was recorded using a low-frequency piezoelectric sensor VS30-V (Vallen-Systeme) with a flat response in the $25-80 \mathrm{kHz}$ frequency bands. The sensor was attached to the specimen surface just outside the gauge length on the unstrained shoulder, using a spring and a silicon grease. The AE signal was amplified by $40 \mathrm{~dB}$ in the frequency band from about $1 \mathrm{kHz}$ to $80 \mathrm{kHz}$. The $\mathrm{AE}$ recording was performed continuously, without applying a threshold, with a 16-bit amplitude resolution and $100 \mathrm{kHz}$ sampling rate. Taking into account that the Nyquist frequency limiting the information obtained from a discrete time series is equal to half the sampling rate [44], i.e., $50 \mathrm{kHz}$, the effective time resolution of the AE measurements is compatible with that of the video recording.

\section{Experimental results}

Figures $1 \mathrm{a}, 1 \mathrm{~b}$ and $1 \mathrm{c}$ show a typical example of synchronous data recording from the sensors of strain (a), load (b), and AE (c) during the spontaneous development of a strain burst under creep conditions. Like in [18], the specimen was initially preloaded to a stress significantly 
exceeding the conditional yield point (160 MPa) in an AlMg6 alloy and kept at this stress level waiting for a spontaneous strain burst (note the abscissa origin indicating the need of an incubation time for the onset of the instability). The example presented in Fig. 1 was obtained for the stress value of $272 \mathrm{MPa}$. Additional instabilities may be initiated by stepwise increasing the stress level.

Fig. 1b shows the respective stress response $\sigma(t)$ containing a series of stress drops with amplitudes of $\sim 3-10 \mathrm{MPa}$ and the front duration of $\sim 1-3 \mathrm{~ms}$. As specified above, this intermittent mechanical response is due to the inertia of the "machine-specimen" system, similar to the occurrence of stress drops during the PLC effect. It should be emphasized that as was shown in [18], each of the stress drops arising during a strain burst in creep conditions is associated, as a rule, with the occurrence of an individual deformation band in the form of a widening neck inclined at an angle of about $60^{\circ}$ to the tensile axis (see a detailed description below). The evolution of each deformation band comprises two successive stages, more precisely, the initial rapid and the following slow stages. The rapid stage with a duration of $\sim 1-3$ ms includes the processes of nucleation of an embryo band on a side surface and its rapid transversal growth (across the specimen width). It is accompanied by an abrupt stress drop with a magnitude up to $\sim 10 \mathrm{MPa}$. The slow stage lasting $\sim 10-100 \mathrm{~ms}$ consists of a smooth (without any irregularities) lateral widening of the deformation band along the tensile axis. It should be underlined that it does not lead to additional unloading but corresponds to a continuous reloading to almost the initial stress level.

At the same time, as can be seen from Figs. $1 \mathrm{~b}$ and 1c, each stress drop is accompanied by an AE burst represented by a sequence of damped oscillations with a decay time of about $30 \mathrm{~ms}$. The first acoustic oscillation in the structure of the AE burst occurs simultaneously with the sharp unloading and, consequently, with the initial rapid stage of the evolution of the deformation band. The subsequent damped oscillations on the rear front of the AE burst occur simultaneously with the continuous stress recovery associated with the slow stage. In can thus be conjectured that the damped oscillations which follow the initial sharp increase with the maximum amplitude $\Delta U_{m}$ in the structure of the AE burst (see Figs. 1c and 2a) are not associated with specific relaxation processes in the deforming material, but are rather caused by the excitation of the natural oscillations of the specimen-machine mechanical system. Thus, only the first acoustic oscillation with a duration of $\sim 1-3 \mathrm{~ms}$ carries real-time information about the band dynamics. 
Moreover, it occurs that the AE and stress responses are not only correlated in time but their intensities are also closely connected. This relation can be uncovered by considering another time series reflecting the plastic instability, namely, the absolute value of the stress derivative $\psi(t)=|d \sigma(t) / d t|$. Such time series were used, e.g., to characterize the plastic flow intermittency under conditions of the PLC effect in AlMg alloys (see [34, 45-48]). As expected from the correlation between the stress and AE time series, Figs. 1c and 1d demonstrate the temporal correlation between the AE signal and the function $\psi(t)$ (see also a magnification in Figs. $2 \mathrm{a}$ and $2 \mathrm{~b}$ ). In its turn, Fig. 3 displays an approximately linear dependence of the AE amplitude $\Delta U_{m}$ as a function of the amplitude of the corresponding peak $\Delta \psi_{m}$, with the correlation coefficient of the linear fit equal to 0.9762 (the calculation was performed in MathCad).

Let us now consider in more detail the early stage of nucleation and evolution of the primary deformation band within a period of $\sim 1 \mathrm{~ms}$ in the structure of the strain burst, in order to understand the fine features of the correlation between the nucleation of a plastic strain localization and the respective patterns of the AE signal and the stress response. The choice of the primary band for such an analysis is justified by the results [18] testifying that the main mechanism of the strain burst development under conditions of discontinuous creep is the multiplication of deformation bands when, except for the primary deformation band, each new band originates at the boundary of the previous one. The primary band nucleates spontaneously in a random position of the gauge length of the specimen and triggers off the strain burst development.

Fig. 4a presents the data of video recording of the initial stage of the evolution of the primary band at an applied stress of $292 \mathrm{MPa}$. As can be seen from these snapshots, plastic deformation is first localized in the form of an embryo band, which appears in a random position at the side surface of the specimen, usually in the middle of its gauge section. After initiation, the band grows across the specimen, forming an angle with the tensile axis, consistent with the resulting band orientation. This process continues until the observed trace becomes a complete band through the entire specimen width. The duration of the transverse growth of a band usually comprises several milliseconds at creep stresses of 250-300 MPa. This finding qualitatively agrees with the pattern of growth of the embryo of a type $B$ PLC band in Al-Mg alloys deformed with a constant imposed strain rate in a hard tensile machine [26, 27, 49-52]. 
Furthermore, the high spatiotemporal resolution of the optical method used (more precisely, $20 \mu \mathrm{m} /$ pixel and $40 \mu \mathrm{s}$ ) allowed for revealing some significant features of the dynamics and morphology of deformation bands. The analysis of the video recorded data associated with more than 30 deformation bands at creep stresses in the range $\sigma_{0}=250-300 \mathrm{MPa}$ suggested the following conclusions:

(i) The embryo band has a needle-like form with an approximately parabolic shape of the band tip. The growth kinetics of an embryo band is characterized by the tip velocity $v_{t}$ and the lateral growth velocity $v_{l}$, which is at least one order of magnitude less than $v_{t}$ (see Fig. $4 \mathrm{a}$ ). The tip velocity vector usually forms an angle of $58-62^{\circ}$ with respect to the tensile axis, which corresponds to the direction of the maximum tangential stresses (for an isotropic plastically deformable flat specimen, the corresponding theoretical value is equal to $55^{\circ} 44^{\prime}$ [53]). Figure $4 \mathrm{~b}$ shows an example of the image processing for the fragment presented in Fig. 4a, in the form of successive contours of the growing band at the same time intervals, in order to demonstrate the accelerating growth of an embryo band. The embryo band tip reaches the opposite edge of the specimen at a point $\mathrm{C}$ at the instant $t_{c r}$. This instant is hereinafter called "critical" in the sense that, first, the tip velocity reaches the maximum value, second, the deformation band becomes fully complete, and finally, it corresponds to the onset of the acoustic and load responses (see below). Therewith, both the length $L_{b}$ and width $w_{b}$ of the embryo band reach their maximum values at this point: $L_{b}\left(t_{c r}\right) \approx 2 d_{s} / \sqrt{3} \approx 3.5 \mathrm{~mm}$, and $w_{b}\left(t_{c r}\right) \approx 2 w_{s} \approx 0.4 \mathrm{~mm}$, where $d_{s}(=3 \mathrm{~mm})$ and $w_{s}(=0.2 \mathrm{~mm})$ are the width and thickness of the specimen, respectively.

(ii) The embryo band growth is essentially non-stationary as the tip velocity continuously increases, especially sharply in the immediate vicinity of the opposite edge of the specimen. In the first third of the development of the embryo-band length (about $1 \mathrm{~mm}$ ), the average tip velocity does not exceed $0.5 \mathrm{~m} / \mathrm{s}$, while at the critical point, when this band passes through the entire cross-section of specimen, the tip velocity reaches a maximum value of about $10 \mathrm{~m} / \mathrm{s}$, and the lateral growth rate is not higher than $10 \mathrm{~cm} / \mathrm{s}$. In the example of Fig. $4, v_{t}\left(t_{c r}\right) \approx 11 \mathrm{~m} / \mathrm{s}$, $v_{l}\left(t_{c r}\right) \approx 5 \mathrm{~cm} / \mathrm{s}$ (see also Fig. 5e). After $t_{c r}$, the dynamics of the complete band is determined by the lateral growth rate $v_{l}$ only. Namely, the lateral growth rate and hence, the rate of the band widening decreases until it stops, and then secondary bands are generated in accordance with the cascade mechanism of the band multiplication [18]. It should be noted that in experiments with a lower temporal resolution (see for example, Ref. [38, 52]), the very rapid stage of the embryo- 
band evolution is not detected and only a projection of the lateral growth rate of the complete band on the tensile axis is measured, i.e. $v_{a}=v_{l} \sin \varphi$.

\section{Discussion}

The results obtained by virtue of time-resolved measurements of the embryo bands and their synchronization with the acoustic and stress responses allow for a thorough comparison with the models of deformation band development known from the literature. Starting from the first works reporting video recording of PLC deformation bands and limited to a low temporal resolution of $25 \mathrm{fps}$, three speculative scenarios for the nucleation and growth of an embryo band were proposed [19]. According to the first scenario, the embryo band nucleates at one side surface and has the same width at the end of its growth across the specimen as at the nucleation. The second scenario assumes an instantaneous nucleation of a very thin (a few atomic planes thick) band over the entire specimen width, which then expands in the direction of the tensile axis until the process is stopped by the stress relaxation. The third "hybrid" scenario combines these two mechanisms, i.e., considers an embryo band having a wedge shape during the transversal growth. A scenario non implying nucleation of an embryo was also proposed recently [51]. The results presented above show that during discontinuous creep an embryo band transversely grows in a qualitative agreement with the third scenario. Moreover, the quantitative reconstruction in Fig. 4b, becoming possible due to the high time resolution of the applied experimental technique, allows for a conjecture that the band growth proceeds in a self-similar manner with a certain ratio between the tip velocity and the lateral growth velocity.

It must be emphasized that the observed non-stationary growth of an embryo band is of particular interest and would require a careful study. Several qualitative observations can be made using the data representation in Fig. 5. It displays details of the time dependences of various responses recorded during the evolution of the primary band, namely, the stress $\sigma$ (a), its derivative $\psi\left(\right.$ b), the acoustic signal $U_{A E}$ (c), the band area, determined as the area between the boundaries of the band, $S_{b}$, and its time derivative $\dot{S}_{b}=d S_{b} / d t$ (d), and the tip velocity $v_{t}$ (e). As can be seen, both the band area rate $\dot{S}_{b}$ and the tip velocity $v_{t}$ reach their maximum values at the critical instant $t_{c r}$, i.e., when the embryo band has grown through the full crosssection of the specimen. As a matter of example, it may be specified that at the final (accelerating) stage of the embryo band growth with a duration of about $0.2 \mathrm{~ms}$, the band area rate increases from $8 \mathrm{~cm}^{2} / \mathrm{s}$ to about $30 \mathrm{~cm}^{2} / \mathrm{s}$ and the tip velocity from $2 \mathrm{~m} / \mathrm{s}$ to $11 \mathrm{~m} / \mathrm{s}$ (see Figs. 
$5 \mathrm{~d}$ and $5 \mathrm{e})$. Fitting of the velocity evolution curve bears witness that the final stage of growth of the band embryo is well approximated by an exponential function $v_{t} \sim \exp (t / \tau)$, where the time constant $\tau \approx 0.13$ ms characterizes the accelerated tip motion (dashed red line in Fig. 5e). Such a correlation testifies indirectly that the band embryo growth is a process with a feedback. The occurrence of a feedback can be understood from the viewpoint of the increasing stress concentration at the embryo head as it gets closer to the opposite specimen side (point $C$ in Fig. 4b), which would increase the velocity of the leading dislocations.

At the same time, sharp changes in the stress response and AE signal only occur after $t_{c r}$. Both the stress drop rate $\psi=|\dot{\sigma}|$ and the AE signal $U_{A E}$ reach their peak values approximately $0.4 \mathrm{~ms}$ after $t_{c r}$ (Figs. 5b and 5c). As a whole, there is a clear correlation of the AE signal with the stress drop rate (see Figs. 5b and 5c), at least until the end of the stress drop (frame 1480 in Fig. 4a). In this time interval, the calculation of the correlation coefficient between the waveform of the AE signal $U_{A E}(t)$ and the function $\psi(t)$ renders quite a high value, $k=0.9853$. Both signals simultaneously reach their maximum values. After the end of the stress drop, the natural frequencies of the mechanical system are excited and the correlation between these signals decreases. On the other hand, the comparison with $\dot{S}_{b}$ and $v_{t}$ in Figs. $5 \mathrm{~d}$ and 5e testifies that the sharp increases in the stress drop rate and the AE signal only commence upon the formation of a complete band. It can thus be suggested that these responses result from the exit of a large number of dislocations to the external surface of the specimen after their motion through the entire cross section.

It is interesting to discuss in this context the nature of the $\mathrm{AE}$ sources pertinent to the studied experimental situation. The following possible dislocation sources of the AE are usually considered in the literature: the relaxation of stresses caused by the motion of dislocations, the acceleration (deceleration) and/or multiplication of dislocations, the disappearance of stress fields due to the dislocations annihilation or exit to the outer crystal surface (reviews [54, 55]). The present results indicate that the main contribution to the AE burst is given by the formation of a complete band, leading to the stress relaxation due to escape of dislocations through the external surface of the specimen. A detailed consideration of the mechanism of AE generation by the dislocations emerging on the specimen surface can be found in $[56,57]$. Furthermore, it may be supposed that when the embryo band reaches the external specimen surface, the overstresses near the band head may relax via at least four possible channels: (i) Breaking the oxide layer that is harder and more brittle than the aluminum matrix; (ii) Formation of a newly exposed stepped 
surface due to the cooperative escape of a large number of dislocations to the external specimen surface. In this case, a part of the strain energy stored in the band will transform into the new surface energy; (iii) Nucleation of a new embryo band orientated in the opposite direction; and (iv) Generation of elastic oscillations, i.e., the AE burst. The coincidence of the AE peak with the emergence of a band on the specimen surface indicates that an essential part of the elastic energy stored in the deformation band is dissipated by the acoustic waves.

Although the precise bands dynamics in the creep conditions may differ from that of the PLC bands, this conjecture agrees with the conclusion based on the conventional AE technique that the PLC bands are accompanied with millisecond AE signals resulting from a close chaining of numerous dislocation avalanches each giving rise to a microsecond-scale AE event [58]. The suggested composite nature of the measured AE signal makes the quantitative analysis of its source quite sophisticated. A possible way to predict the AE in this case may be a physically based numerical modeling like that implemented for the PLC effect [40, 59]. Nevertheless, taking into account the mechanism of the occurrence of stress drops which represent the elastic response of the machine-specimen system to the strain bursts, it may be noted that the proportionality observed between the amplitudes of the AE and stress drop rate signals (Fig. 3) qualitatively agrees with the predictions of a relationship between the AE amplitude and the plastic strain rate, following from the consideration of dislocation avalanches in the absence of macroscopic plastic instabilities $[4,5,60]$. A further progress in the understanding of the specific AE sources under conditions of discontinuous creep would require a comparison of the low-frequency and the conventional high-frequency recording of the $\mathrm{AE}$, which might discriminate between the contributions from the elementary AE sources and their cooperative effect.

\section{Conclusions}

The present paper examines the correlations between the dynamics of the deformation bands recorded using a high-speed digital video with a sampling rate of $25000 \mathrm{fps}$ and the temporal patterns of the load and $\mathrm{AE}$ responses during discontinuous creep in an $\mathrm{AlMg}$ polycrystal at room temperature. The main results can be summarized as follows:

(i) It is observed that the plastic deformation instability starts with the nucleation and the subsequent widening of the primary deformation band which is a trigger of the development of a macroscopic strain burst, i.e., a strain step on the creep curve with an amplitude of several 
percent and the front duration of $0.5-0.7 \mathrm{~s}$. The formation of the primary and the following deformation bands is accompanied by stress drops and discrete AE signals.

(ii) The fastest stage in the evolution of a deformation band corresponds to the nucleation and growth of a needle-like embryo band. The embryo of the primary band is initiated in a random position at a thin lateral surface of the flat specimen and grows across the wide surface at an angle of about $60^{\circ}$ with respect to the tensile axis. The tip velocity of the embryo band gradually increases and reaches a maximum value of about $10 \mathrm{~m} / \mathrm{s}$ at the time instant when the band intersects the opposite lateral surface, i.e., when is has grown through the entire cross-section of the specimen. Afterwards, the complete band dynamics is only determined by the widening rate, i.e., the lateral growth velocity, which usually does not exceed approximately $10 \mathrm{~cm} / \mathrm{s}$.

(iii) The results show that both the stress drop and the AE burst start immediately after the formation of a complete band, and the first peak in the AE burst with the rise time of $\sim 1 \mathrm{~ms}$ correlates well with the peak of the stress drop rate. Moreover, a linear dependence between their amplitudes is established (Fig. 3). These results confirm that the AE provides a physically based measurement of the energy dissipated during the development of plastic instability. The observed relation between $|\dot{\sigma}|$ and $U_{\mathrm{AE}}$ is interesting as a direct experimental evidence justifying statistical studies of AE accompanying mechanical testing of crystals (e.g. [31-35]). Usually, the conclusion on the correlation between the $\mathrm{AE}$ and the plastic instability is based on the observation of bursts in the $\mathrm{AE}$ activity (either count rate or cumulated duration of $\mathrm{AE}$ events) correlated with stress drops $[48,61]$. However, the microsecond resolution of the conventional $\mathrm{AE}$ techniques, which has an advantage of detecting $\mathrm{AE}$ events corresponding to individual dislocation avalanches, hides at the same time information on the integral AE cumulated during the development of a single stress drop [48, 58]. The observed amplitude relationship confirms the above suggestion that the most probable mechanism for generation an AE signal is the formation of a complete band due to nucleation and rapid movement of a large number dislocations through the total cross-section and their emergence to the external surface of the specimen.

This relationship also has a practical interest suggesting that the AE signal may serve as a measure of the rate of change of the load response. An important consequence of it is that the AE measurements may allow, at least, under conditions of discontinuous creep, for getting real-time information about the stress drop rate, i.e., the peaks of the function $\psi$, and the number of deformation bands, without using a load sensor and a video camera. This knowledge may be useful for the control of the operation of metallic constructions. 
In summary, it is noteworthy that in terms of nonlinear dynamics, the spontaneous formation of a deformation band, which causes non-stationary 1D responses of the stress and AE signal under action of a constant external load, i.e., under the creep conditions, is an excellent example of a non-linear phenomenon in materials science, with many analogs in physical, chemical, and biological systems of different nature, when instabilities in the form of spatiotemporal patterns spontaneously arise and propagate in a dynamically defined system [62]. From the practical point of view, the observed correlations between AE signals and bandformation processes can serve as a scientific basis for the development of methods for the early diagnostics of strain localizations in alloys prone to discontinuous creep. It may be expected that the further investigations of correlations between the deformation band dynamics and the acoustic and stress responses would allow to identify the events of unstable plastic deformation using characteristics of AE signals and reveal correlations between such events on the sole basis of AE measurements, which is challenging for practical applications.

\section{Acknowledgements}

This research was supported by the Russian Science Foundation (project No. 18-19-00304) and the Russian Foundation for Basic Research (project No. 19-08-00395) with the use of equipment of the Center of Collective Use of Tambov State University. M.L. gratefully acknowledges support from the French State through the program "Investment in the future" operated by the National Research Agency, in the framework of the LabEx DAMAS [ANR-11-LABX-0008-01] and the research program RESEM managed by IRT M2P (Institut de Recherche Technologique en Matériaux, Métallurgie et Procédés). 


\section{References}

[1] V.N. Rozhanski, Nonuniformities in the plastic deformation of crystals, Uspekhi Fizicheskikh Nauk 65 (1958) 387-406. https://doi.org/10.3367/UFNr.0065.195807b.0387

[2] V.V. Shpeizman, N.N. Peschanskaya, B.I. Smirnov, Nonmonotonic creep in LIF crystals containing Mg, Phys. Solid State 40 (1998) 634-637. https://doi.org/ 10.1134/1.1130368

[3] G.W. Ardley, A.H. Cottrell, Yield points in brass crystals, Proc. Roy. Soc. A. 219 (1953) 328-334. https://doi.org/10.1098/rspa.1953.0150

[4] J. Weiss, J.-R. Grasso, Acoustic Emission in Single Crystals of Ice, J. Phys. Chem. B. 101 (1997) 6113-6117. https://doi.org/10.1021/jp963157f

[5] M.C. Miguel, A. Vesplignani, S. Zapperi, J. Weiss, J.-R. Grasso, Intermittent plastic flow in viscoplastic deformation, Nature 410 (2001) 667-671. https://doi.org/ 10.1038/35070524

[6] N.N. Peschanskaya, P.N. Yakushev, V.M. Egorov, V.A. Bershtein, L. Bokobza, Discontinuous deformation and morphology of polymers, Phys. Solid State 44 (2002) 1684.1688. https://doi.org/10.1134/1.1507248

[7] A. Portevin, F. Le Chatelier, Sur un phénomène observé lors de l'essai de traction d'alliages en cours de transformation, C.R. Acad. Sci. Paris. 176 (1923) 507-510.

[8] F. Savart, Recherches sur les vibrations longitudinales, Ann. Chim. Fhys. 65 (1837) 337402.

[9] E.N. da C. Andrade, On the viscous flow in metals and allied phenomena, Proc. Roy. Soc. 84 (1910) 1-12.

[10] R.L. Klueh, J.F. King, Unusual creep behavior in a commercial nickel-chromium alloy, Scr. Metall. 13 (1979) 205-209. https://doi.org/10.1016/0036-9748(79)90295-3

[11] R.L. Klueh, J.F. King, Creep and creep rupture of ERNiCr-3 weld metal, Nuclear Mater. 98 (1981) 173-189. https://doi.org/10.1016/0022-3115(81)90398-6

[12] R.L. Klueh, Discontinuous creep in short-range order alloys, Mater. Sci. Eng. 54 (1982) 65-80. https://doi.org/10.1016/0025-5416(82)90030-1

[13] T.L. Silveira, S.N. Monteiro, Jumps in the creep curve of austenitic stainless steels, Metall. Trans. A 10 (1979) 1795-1796. https://doi.org/10.1007/BF02811718

[14] S.N. Monteiro, T.L. Silveira, I. LeMay, On the nature of strain perturbations in the creep nerves of austenitic stainless steel, Scr. Metall. 15 (1981) 957-960. https://doi.org/10.1016/0036-9748(81)90286-6

[15] V.K. Sikka, S.V. David, Discontinuos creep deformation in a type 316 stainless steel casting, Metall. Trans. A 12 (1981) 883-892. https://doi.org/10.1007/BF02648353

[16] J. Kariya, H. Oikawa, S. Karashina, Discontinuous flow in steady-state creep of Al-Mg alloys at high temperatures, Trans. Jpn. Inst. Met. 14 (1973) 327-328. https://doi.org/10.2320/matertrans 1960.14.327 
[17] M. Hamersky, P. Lukac, Z. Trojanova, E. Pink, Creep of Al-3wt \%Mg as measured with the incremental loading method, Mater. Sci. Eng. A 148 (1991) 7-14. https://doi.org/10.1016/0921-5093(91)90860-P

[18] A.A. Shibkov, M.F. Gasanov, M.A. Zheltov, A.E. Zolotov, V.I. Ivolgin, Intermittent plasticity associated with the spatio-temporal dynamics of deformation bands during creep tests in an AlMg polycrystal, Int. J. Plast. $86 \quad$ (2016) 37-55. https://doi.org/10.1016/j.ijplas.2016.07.014

[19] K. Chihab, Y. Estrin, L.P. Kubin, J. Vergnol, The kinetics of the Portevin-Le Chatelier bands in an Al-5 at\%Mg alloy, Scr. Metall. 21 (1987) 203-208. https://doi.org/10.1016/0036-9748(87)90435-2

[20] D. Yuzbekova, A. Mogucheva, D. Zhemchuzhnikova, T. Lebedkina, M. Lebyodkin, R. Kaibyshev, Effect of microstructure on continuous propagation of the Portevin-Le Chatelier deformation bands, Int. J. Plast. $96 \quad$ (2017) 210-226. https://doi.org/10.1016/j.ijplas.2017.05.004

[21] M. Mehenni, H. Ait-Amokhtar, C. Fressengeas, Spatiotemporal correlations in the Portevin-Le Chatelier band dynamics during the type B - type C transition, Mater. Sci. Eng. A 756 (2019) 313-318. https://doi.org/10.1016/j.msea.2019.04.036

[22] B. Reyne, P.-Y. Manach, N. Moes, Macroscopic consequences of Piobert-Lüders and Portevin-Le Chatelier bands during tensile deformation in Al-Mg alloys, Mater. Sci. Eng. A 746 (2019) 187-196. https://doi.org/10.1016/j.msea.2019.01.009

[23] L.P. Kubin, C. Fressengeas, G. Ananthakrishna, Collective behaviour of dislocations. In: Nabarro FRN, Duesbery MS, editors. Dislocations in solids, Elsevier, Amsterdam; 2002, p. 101-192.

[24] R.B. Schwarz, L.L. Funk, Kinetics of the Portevin-Le Chatelier effect in an Al 6061 alloy, Acta metall. 33 (1985) 295-307. https://doi.org/10.1016/0001-6160(85)90148-8

[25] L. Casarotto L, R. Tutsch, R. Ritter, J. Weidenmuller, A. Ziegenbein, F. Klose, H. Neuhäuser, Propagation of deformation bands investigated by laser scanning extensometry, Comput. Mater. Sci. 26 (2003) 210-218. https://doi.org/10.1016/S0927-0256(02)00401-9

[26] W. Tong, H. Tao, N. Zhang, L.G. Hector Jr., Time-resolved strain mapping measurements of individual Portevin-Le Chatelier deformation bands, Scripta Mater. 53 (2005) 87-92. https://doi.org/10.1016/j.scriptamat.2005.03.020

[27] G.F. Xiang, Q.C. Zhang, H.W. Liu, X.P. Wu, X.Y. Ju, Time-resolved deformation measurements of the Portevin-Le Chatelier bands, Scr. Mater. 56 (2007) 721-724. https://doi.org/10.1016/j.scriptamat.2006.08.049

[28] A.J. Yilmaz, The Portevin-Le Chatelier effect: a review of experimental findings, Sci. Technol. Adv. Mater. 12 (2011) 1-16. https://doi.org/10.1088/1468-6996/12/6/063001 
[29] W.F. Hartman, Acoustic emission and the Portevin-Le Chatelier effect, Experimental Mechanics 14 (1974) 19-23. https://doi.org/10.1007/BF02324855

[30] R. Král, P. Dobroň, F. Chmelík, V. Koula, M. Rydlo, M. Janeček, A qualitatively new approach to acoustic emission measurements and its application to pure aluminium and Mg-Al alloys, Kovove Mater. 45 (2007) 159-163.

[31] M.A. Lebyodkin, T.A. Lebedkina, F. Chmelik, T.T. Lamark, Y. Estrin, C. Fressengeas, J. Weiss, Intrinsic structure of acoustic emission events during jerky flow in an Al alloy, Phys. Rev. B 79 (2009) 174114-9. https://doi.org/10.1103/PhysRevB.79.174114

[32] I.V. Shashkov, M.A. Lebyodkin, T.A. Lebedkina, Multiscale study of acoustic emission during smooth and jerky flow in an AlMg alloy, Acta. Mater. 60 (2012) 6842-6850. https://doi.org/10.1016/j.actamat.2012.08.058

[33] A. Vinogradov, D. Orlov, A. Danyuk, Y. Estrin, Effect of grain size on the mechanisms of plastic deformation in wrought $\mathrm{Mg}-\mathrm{Zn}-\mathrm{Zr}$ alloy revealed by acoustic emission measurements, $\quad$ Acta $\quad$ Mater. $61 \quad$ (2013) 2044-2056. https://doi.org/10.1016/j.actamat.2012.12.024

[34] M.A. Lebyodkin, I.V. Shashkov, T.A. Lebedkina, V.S. Gornakov, Experimental investigation of the effect of thresholding on temporal statistics of avalanches, Phys. Rev. E. 95 (2017) 032910. https://doi.org/10.1103/PhysRevE.95.032910

[35] T.A. Lebedkina, D.A. Zhemchuzhnikova, M.A. Lebyodkin, Correlation versus randomization of jerky flow in an AlMgScZr alloy using acoustic emission, Phys. Rev. E 97 (2018) 013001. https://doi.org/10.1103/PhysRevE.97.013001

[36] F. Su, T. Li, X. Pan, M. Miao, Acoustic emission responses of three typical metals during plastic and creep deformations, Experimental Techniques 42 (2018) 685-691. https://doi.org/10.1007/s40799-018-0274-x

[37] J. Petit, G. Montay, M. Francois, Strain localization in mild (low carbon) steel observed by acoustic emission - ESPI coupling during tensile test, Experimental Mechanics 58 (2018) 743-758. https://doi.org/10.1007/s11340-018-0379-2

[38] H. Louche, K. Bouabdallah, P. Vacher, T. Coudert, P. Balland, Kinematic fields and acoustic observations associated with the Portevin-Le Chatelier effect on an Al-Mg alloy, Experimental Mechanics 48 (2008) 741-751. https://doi.org/10.1007/s11340-008-9125-5

[39] J.M. Reed, M.E. Walter, Observations of serration characteristics and acoustic emission during serrated flow of an Al-Mg alloy, Mater. Sci. Eng. A 359 (2003) 1-10. https://doi.org/10.1016/S0921-5093(02)00729-3

[40] J. Kumar, R. Sarmah, G. Ananthakrishna, General framework for acoustic emission during plastic deformation, Phys. Rev. B 92 (2015) 144109.

https://doi.org/10.1103/PhysRevB.92.144109 
[41] A. Vinogradov, A. Lasarev, Continuous acoustic emission during intermittent plastic flow in $\alpha$-brass, Scr. Mater. 66 (2012) 745-748. https://doi.org/10.1016/j.scriptamat.2012.01.053

[42] A. Vinogradov, V. Patlan, S. Hashimoto, Spectral analysis of acoustic emission during cyclic deformation of copper single crystals, Philos. Mag. 81 (2001) 1427-1446. https://doi.org/10.1080/01418610108214356

[43] A. Lazarev, A. Vinogradov, About plastic instabilities in iron and power spectrum of acoustic emission, J. Acoust. Emission. 27 (2009) 144-156.

[44] E. Onajite, Understanding Sample Data, in: Seismic data analysis in hydrocarbon exploration, Elsevier B.V., 2014, pp. 105-115. https://doi.org/10.1016/B978-0-12-420023$\underline{4.00008-3}$

[45] M.S. Bharathi, M. Lebyodkin, G. Ananthakrishna, C. Fressengeas, L.P. Kubin, Multifractal burst in the spatiotemporal dynamics of jerky flow, Phys. Rev. Lett. 87 (2001) 165508. https://doi.org/10.1103/PhysRevLett.87.165508

[46] M.A. Lebyodkin, T.A. Lebedkina, Multifractal analysis of evolving noise associated with unstable plastic flow, Phys. Rev. E $73 \quad$ (2006) 036114. https://doi.org/10.1103/PhysRevE.73.036114

[47] M.A. Lebyodkin, N.P. Kobelev, Y. Bougherira, D. Entemeyer, C. Fressengeas, T.A. Lebedkina, I.V. Shashkov, On the similarity of plastic flow processes during smooth and jerky flow in dilute alloys, Acta Mater. 60 (2012) 844-850. https://doi.org/10.1016/j.actamat.2011.10.042

[48] M.A. Lebyodkin, N.P. Kobelev, Y. Bougherira, D. Entemeyer, C. Fressengeas, V.S. Gornakov, T.A. Lebedkina, I.V. Shashkov, On the similarity of plastic flow processes during smooth and jerky flow: Statistical analysis, Acta Mater. 60 (2012) 3729-3740. https://doi.org/10.1016/j.actamat.2012.03.026

[49] M.M. Krishtal, A.K. Khrustalev, A.V. Volkov, S.A. Borodin, Nucleation and growth of macrofluctuations of plastic strain with discontinuous yield and luders deformation: Results of high-speed video filming, Dokl. Phys. 54 (2009) 225-229. https://doi.org/10.1134/S1028335809050024

[50] J. Zdunek, T. Brynk, J. Mizera, Z. Pakiela, K. J. Kurzydlowski, Digital image correlation investigation of Portevin-Le Chatelier effect in an aluminium alloy, Material characterization 59 (2008) 1429-1433. https://doi.org/10.1016/j.matchar.2008.01.004

[51] M.A. Lebyodkin, D.A. Zhemchuzhnikova, T.A. Lebedkina, E.C. Aifantis, Kinematics of formation and cessation of type $\mathrm{B}$ deformation bands during the Portevin-Le Chatelier effect in an AlMg alloy, Results in Physics 12 (2019) 867-869. https://doi.org/10.1016/j.rinp.2018.12.067 
[52] V.V. Gorbatenko, V.I. Danilov, L.B. Zuev, Plastic flow instability: Chernov-Lüders bands and the Portevin-Le Chatelier effect, Technical Physics. The Russian Journal of Applied Physics 62 (2017) 395-400. https://doi.org/10.1134/S1063784217030082

[53] R. Hill, The mathematical theory of plasticity, Clarendon: Oxford; 1998.

[54] V. S. Boiko, V. D. Natsik, Elementary dislocation mechanisms of acoustic emission, in: Elementary Processes of Plastic Deformation of Metals [in Russian], Naukova Dumka, Kiev, 1978, pp. 159-189.

[55] K. Mathis, F. Chmelik, Exploring Plastic Deformation of Metallic Materials by the Acoustic Emission Technique, in: Acoustic Emission, Ed. by Wojciech Sikorski, 2012, pp. 23-48.

[56] V.D. Natsik, Radiation of sound by a dislocation emerging to the surface of a crystal, JETP Letters 8 (1968) 324-327.

[57] V.D. Natsik, A.N. Chishko, Sound radiation of dislocations moving near a surface of crystal, Fizika tverdogo tela 20 (1978) 457-465.

[58] T.A. Lebedkina, Y. Bougherira, D. Entemeyer, M.A. Lebyodkin, I.V. Shashkov, Crossover in the scale-free statistics of acoustic emission associated with the Portevin-Le Chatelier instability, $\quad$ Scripta $\quad$ Mater. $\quad 148 \quad$ (2018) 47-50. https//:doi.org/10.1016/j.scriptamat.2018.01.017

[59] J. Kumar, G. Ananthakrishna, Modeling the complexity of acoustic emission during intermittent plastic deformation: Power laws and multifractal spectra, Phys. Rev. E 97 (2018) 012201. https//:doi.org/10.1103/PhysRevE.97.012201

[60] J. Weiss, T. Richeton, F. Louchet, F. Chmelık, P. Dobron, D. Entemeyer, M. Lebyodkin, T. Lebedkina, C. Fressengeas, R.J. McDonald, Evidence for universal intermittent crystal plasticity from acoustic emission and high-resolution extensometry experiments, Phys. Rev. B 76 (2007) 224110. https://doi.org/ 10.1103/PhysRevB.76.224110

[61] F. Chmelík, A. Ziegenbein, H. Neuhäuser, P. Lukáč, Investigating the Portevin-Le Chatelier effect by the acoustic emission and laser extensometry techniques, Mater. Sci. Eng. A 324 (2002) 200-207. https://doi.org/10.1016/S0921-5093(01)01312-0

[62] D.A. Kessler, J.A. Koplik, H. Levine, Pattern selection in fingered growth phenomena, Adv. Phys. 37 (1988) 255-339. https://doi.org/10.1080/00018738800101379 


\section{Figure captions}

Fig. 1. (a) Strain step $\Delta \varepsilon(t)$ on the creep curve at the applied creep stress $\sigma_{0}=272 \mathrm{MPa}$. (b) The respective serrated load response $\sigma(t)$. (c) The discrete acoustic response, i.e., the AE signal $U_{A E}(t)$. (d) The time dependence of the absolute value of the time derivative of stress, $\psi(t)=|\dot{\sigma}(t)|$. Vertical arrow denotes the instant of nucleation of the primary deformation band. Vertical dotted lines establish correspondences between the stress drops and the first peaks in the $\mathrm{AE}$ burst structure, caused by the formation of deformation bands, and the corresponding peaks of the function $\psi(t)$.

Fig. 2. Examples of the shapes of an $\mathrm{AE}$ burst $U_{\mathrm{AE}}$ (a) and the corresponding stress drop rate $\psi$ (b), caused by the formation on an individual deformation band during discontinuous creep at $\sigma_{0}=272 \mathrm{MPa} . \Delta U_{\mathrm{m}}$ and $\Delta \psi_{\mathrm{m}}$ denote the amplitudes of the AE signal and the stress drop rate peak, respectively.

Fig. 3. Plot of $\Delta U_{\mathrm{m}}$ vs $\Delta \psi_{\mathrm{m}}$ at $\sigma_{0}=272 \mathrm{MPa}$. The error bar in the inset presents the average error of the data points.

Fig. 4. (a) Formation of the primary deformation band triggering off the strain burst development in an AlMg6 alloy under creep condition at $\sigma_{0}=292 \mathrm{MPa}$. The respective frame numbers are indicated. The sampling rate of 25000 fps corresponds to the time intervals of $40 \mu$ s between the successive images. The tension axis is horizontal.

(b) Contours of the embryo band at various times after nucleation: $1-1.2 \mathrm{~ms}, 2-2.4 \mathrm{~ms}, 3-$ $3.6 \mathrm{~ms}$ (frames 1390, 1420 and 1450, respectively). The interval OC gives the maximum length of the embryo band. $\varphi \approx 60^{\circ}$.

Fig. 5. Time dependences of various responses to the formation of the primary deformation band: (a) the stress $\sigma$, (b) the function $\psi$ obtained by the stress derivation, (c) the AE signal $U_{A E}$, (d) the band area $S_{b}$ (left axis, blue rectangles) and its derivative $\dot{S}_{b}$ (right axis, brown circles), and (e) the tip velocity $v_{t}(\mathrm{e})$. Numbers indicate the frame numbers in Fig. 4a. Vertical arrow in Fig. 5e indicates termination of the transverse growth of the embryo band (frame 1457) at the instant $t_{c r}$. The curved dashed line illustrates the fitting of the last stage of the tip velocity evolution by an exponential function. 

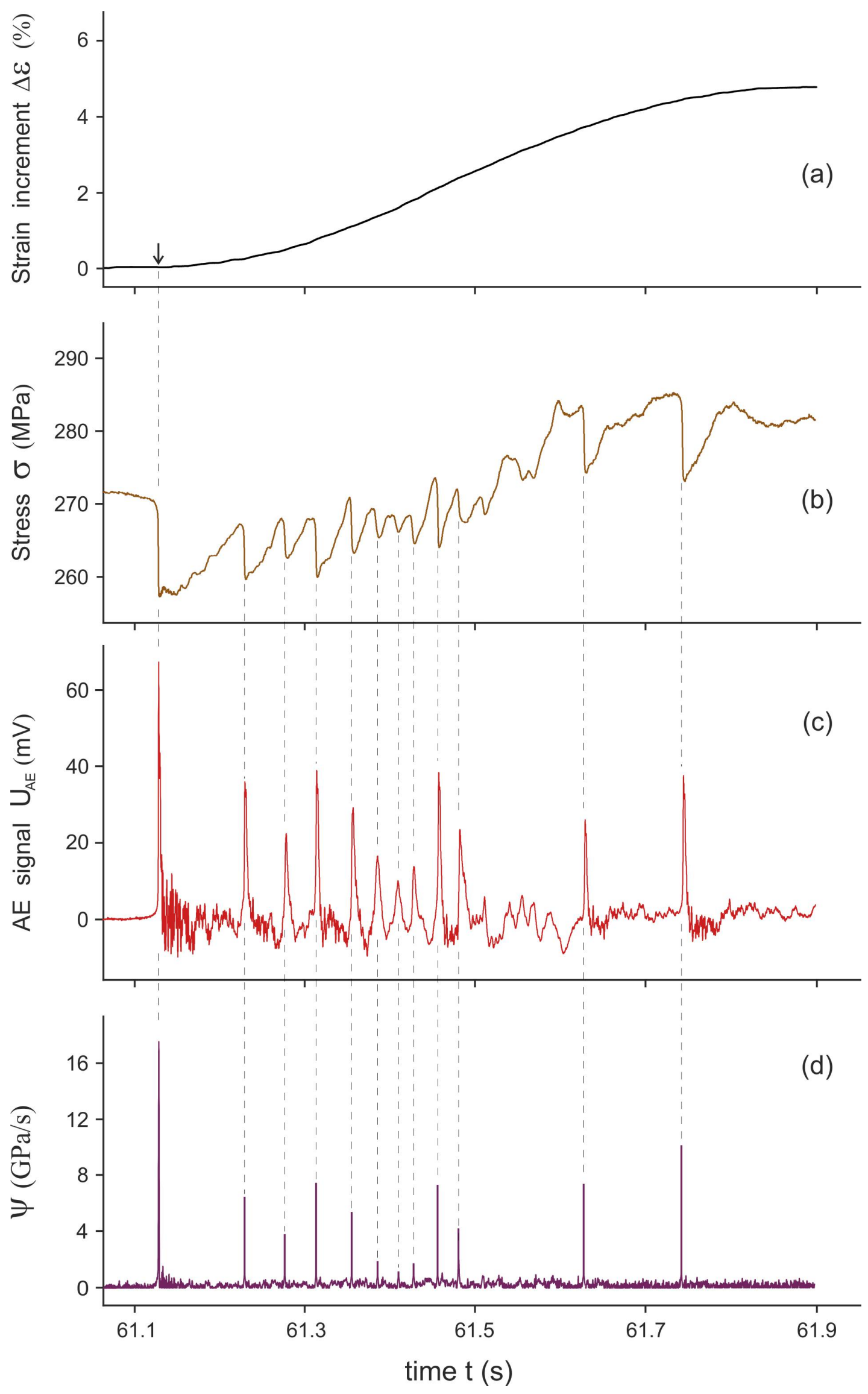

Figure 1 

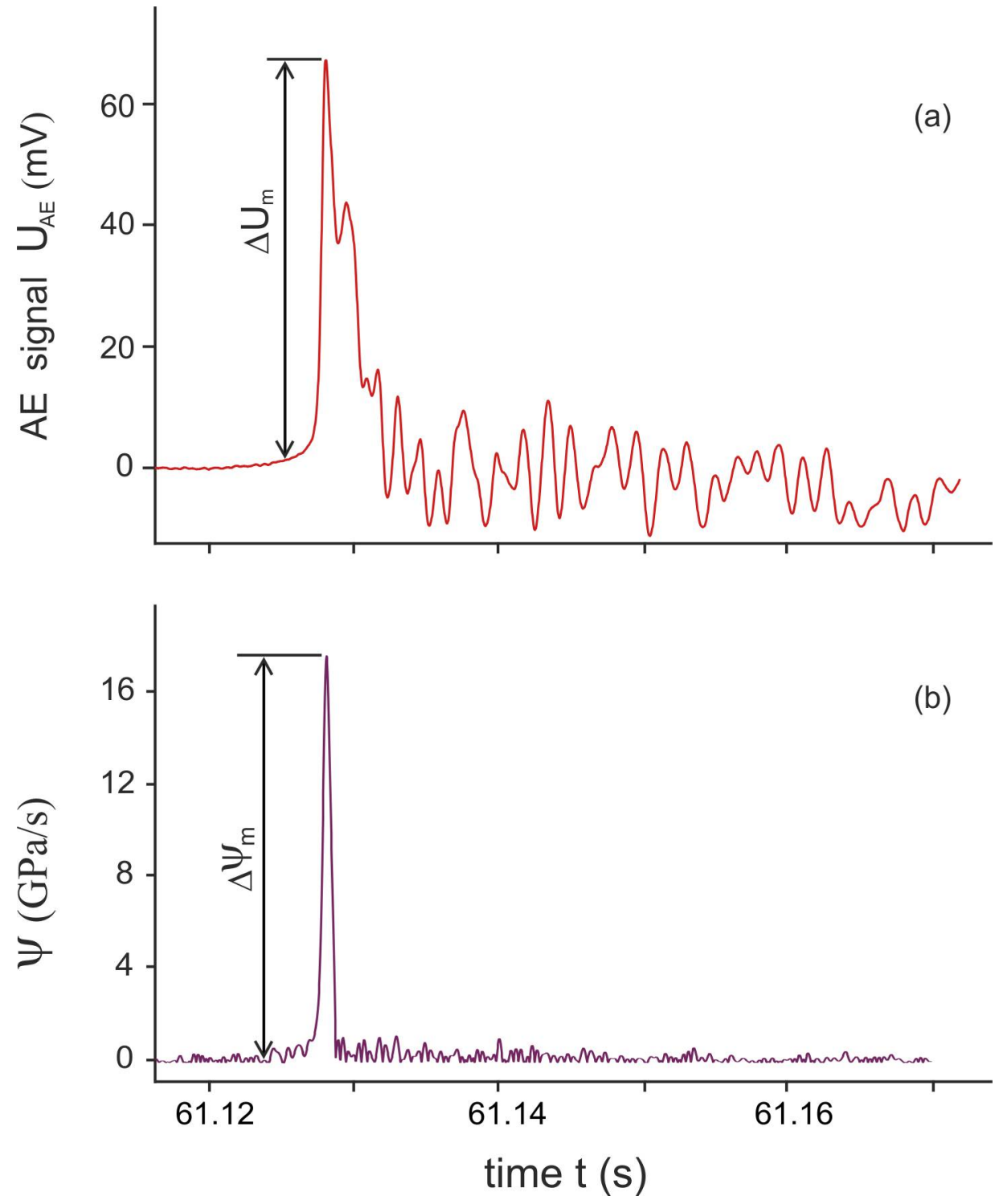

Figure 2 


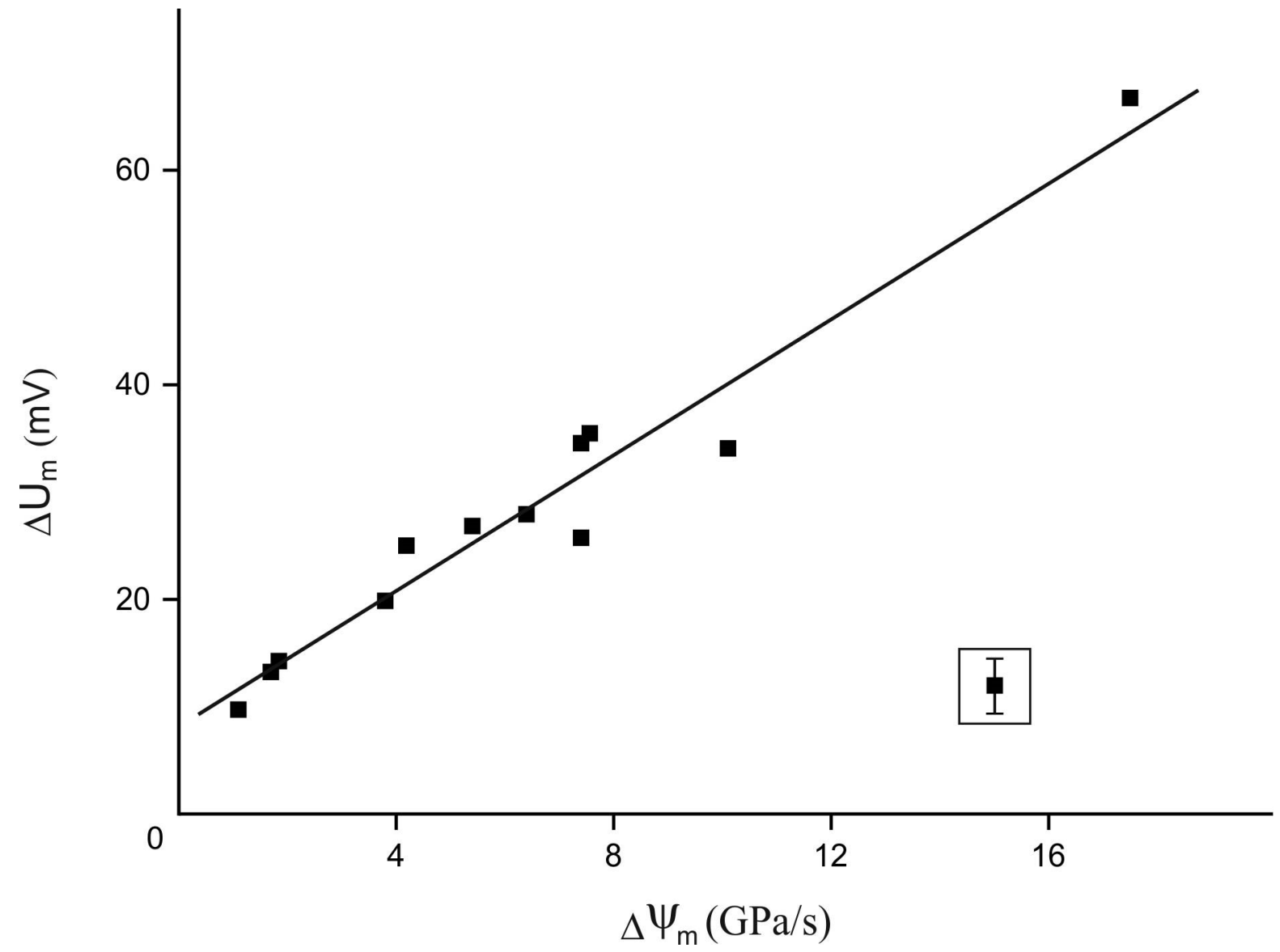

Figure 3 
(a)

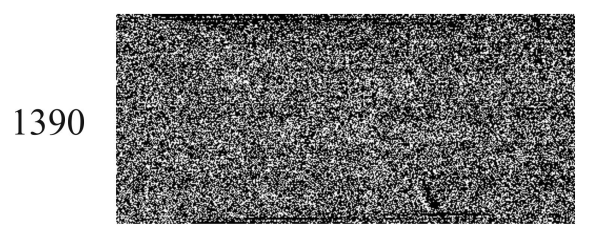

1454
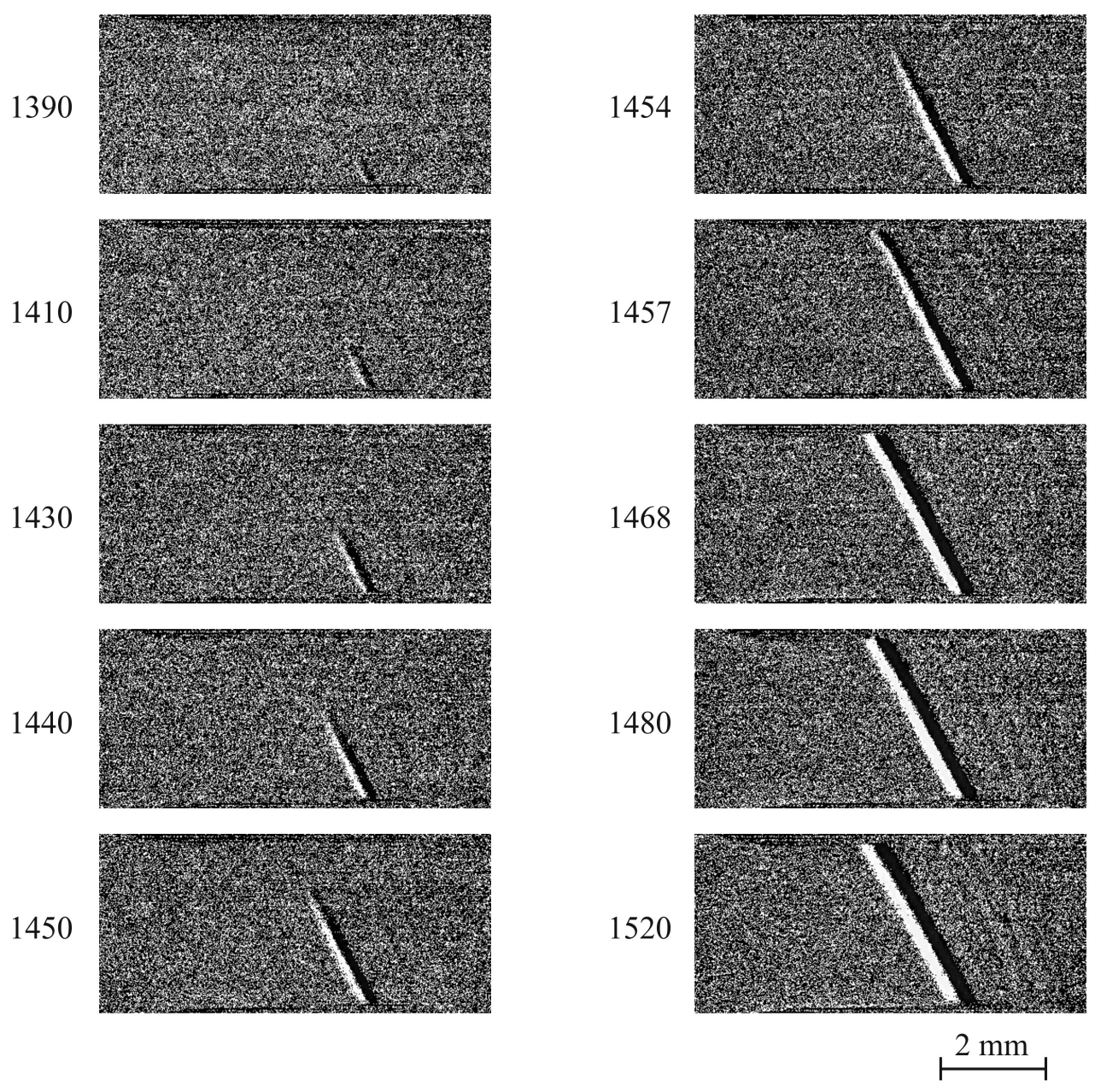

(b)

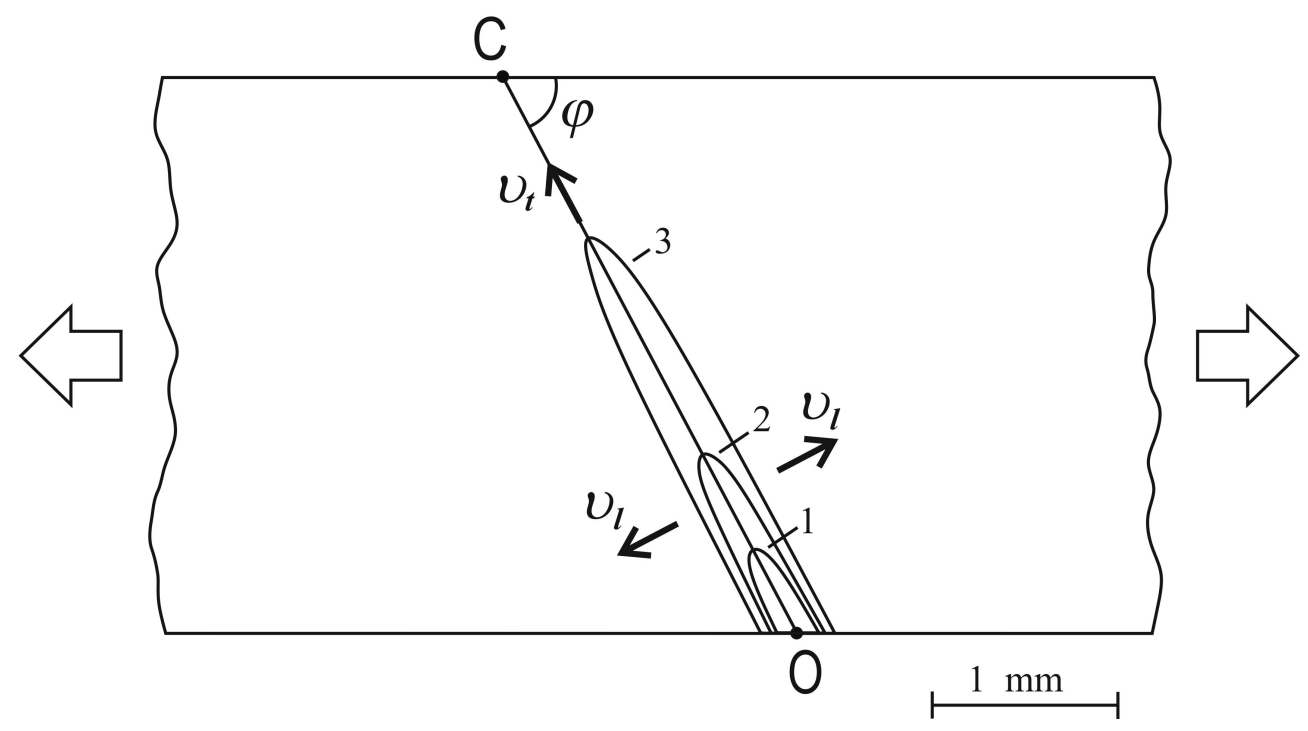

Figure 4 

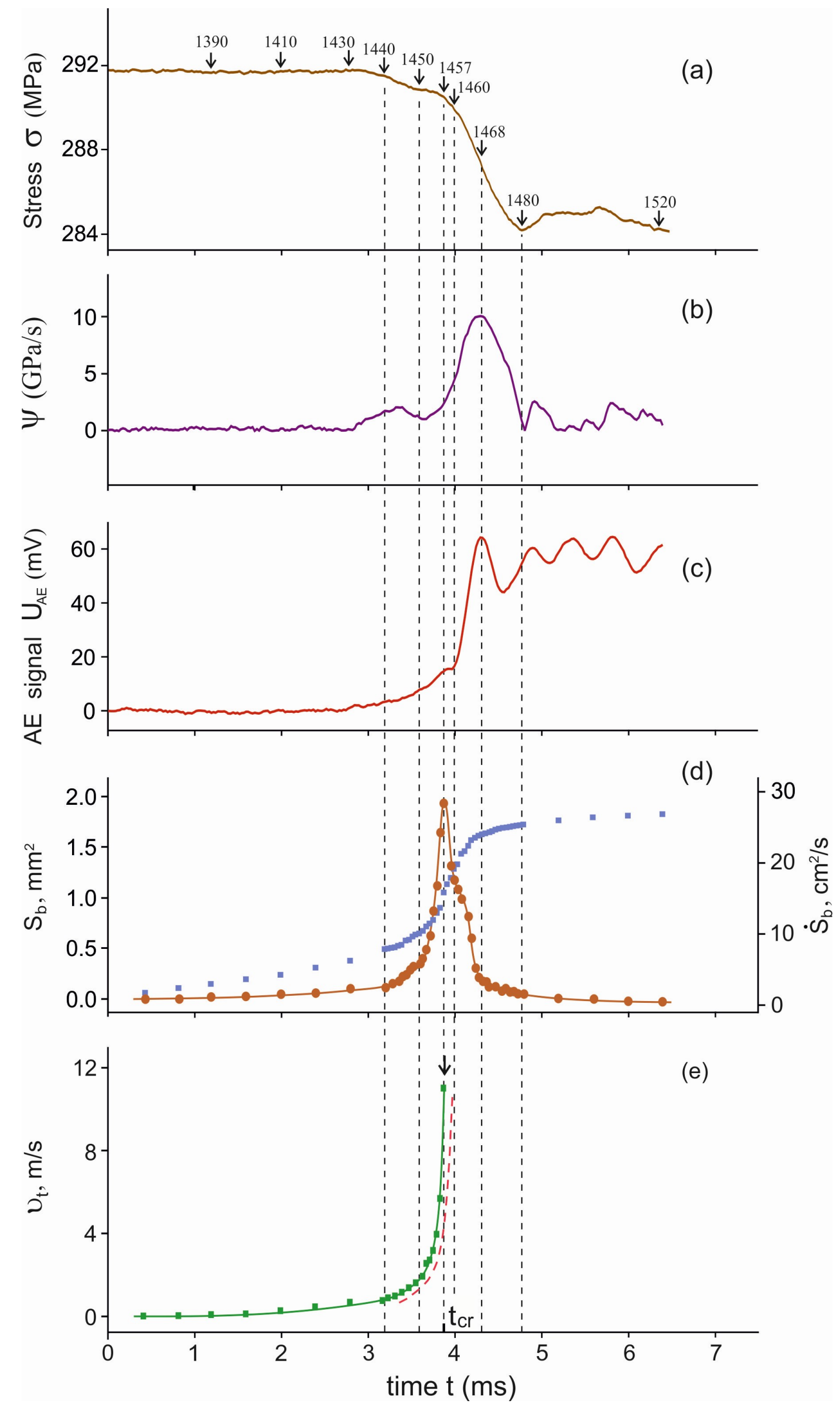

Figure 5 